\title{
Non-traumatic chest pain in patients presenting to an urban emergency Department in sub Saharan Africa: a prospective cohort study in Tanzania
}

Amour S. Mohamed ${ }^{1}$, Hendry R. Sawe ${ }^{1,2^{*}}$ (D, Biita Muhanuzi ${ }^{1}$, Nafsa R. Marombwa' ${ }^{1}$ Kilalo Mjema ${ }^{1}$ and Ellen J. Weber ${ }^{3}$

\begin{abstract}
Background: Non-traumatic chest pain (NTCP) is a common reason for emergency department (ED) attendance in high-income countries, with the primary concern focused on life threatening cardiovascular diseases. There is general lack of data on aetiologies, diagnosis and management of NTPC in Sub Sahara African (SSA) countries. We aimed to describe evaluation, diagnosis and outcomes of adult patients presenting with NTCP to an urban ED in Tanzania.

Method: This was a prospective observational cohort study of consecutive adult ( $\geq 18$ years) patients presenting with non-traumatic chest pain to the Emergency Medicine Department (EMD) of Muhimbili National Hospital (MNH) in Dar es salaam from September 2017 to April 2018. Structured case report form was used to collected demographics, clinical presentation, investigations, diagnosis, and EMD disposition and in hospital mortality. We determined frequency of NTCP among our patients, aetiologies, 24-h and 7-day in-hospital mortality, and predictors for mortality.

Results: We screened 29,495 adults attending EMD-MNH during the study and 389 (1.3\%) presented with NTCP of these, 349 (90\%) were enrolled. The median age was 45 (IQR 29-60) years and 177 (50.7\%) were female. Overall, $69.1 \%$ patients received electrocardiography (ECG) in the EMD and $34.1 \%$ had a troponin test. Heart failure and pulmonary tuberculosis (PTB) were the leading hospital diagnoses (12.6\% each), followed by chronic kidney disease (10\%) and acute coronary syndrome (ACS) (9.6\%). Total of 167 (48\%) patients were admitted, and the 24-h and 7day in-hospital mortality were $5(3 \%)$ and $16(9.6 \%)$ respectively. Univariate risk factors for mortality were a Glasgow Coma Scale of $<15[R R=3.4(95 \% \mathrm{Cl} 3.2-23)]$, Acute Coronary Syndrome $[R R=5.7$ (95\% Cl 1.7-11.8) and Troponin > $0.04 \mathrm{ng} / \mathrm{ml}$ [RR $2.9(95 \% \mathrm{Cl} 1.2-7.3)]$. Features distinguishing cardiovascular from other causes were: bradycardia $[R R=2.6(95 \% \mathrm{Cl} 2.1-3.2)]$, heart beat awareness $[\mathrm{RR}=2.3(95 \% \mathrm{Cl} 1.7-3.2)]$ and history of diabetic mellitus $[\mathrm{RR}=2.2$ (95\% Cl 1.6-3.0)].
\end{abstract}

Conclusion: In this ED of SSA country, heart failure and pulmonary tuberculosis were the leading causes of NCTP, and ACS was present in 9.6\%. NTCP in this setting carries high mortality, and ACS was the leading risk factor for death. ED providers in SSA must increasingly consider cardiovascular causes of NTCP.

Keywords: Chest pain, Emergency department, Non-traumatic chest pain, Sub Sahara Africa, Tanzania, Acute coronary syndrome, Tuberculosis

\footnotetext{
* Correspondence: hendry_sawe@yahoo.com

'Emergency Medicine Department, Muhimbili University of Health and Allied

Science, P.O. Box 65001, Dar es Salaam, Tanzania

${ }^{2}$ Emergency Medicine Department, Muhimbili National Hospital, Dar es

Salaam, Tanzania

Full list of author information is available at the end of the article
}

(c) The Author(s). 2019 Open Access This article is distributed under the terms of the Creative Commons Attribution 4.0 International License (http://creativecommons.org/licenses/by/4.0/), which permits unrestricted use, distribution, and reproduction in any medium, provided you give appropriate credit to the original author(s) and the source, provide a link to the Creative Commons license, and indicate if changes were made. The Creative Commons Public Domain Dedication waiver (http://creativecommons.org/publicdomain/zero/1.0/) applies to the data made available in this article, unless otherwise stated. 


\section{Background}

Globally, non-traumatic chest pain (NTCP) is a significant problem which affect about $20-40 \%$ of the general population in their lifetime $[1,2]$. NTCP is common cause of visits to the emergency department (ED). It is a symptom with a broad differential diagnosis [3], including potentially lethal causes such as Acute Coronary Syndrome (ACS), aortic dissection, and pulmonary embolism [3, 4]. Thus, NTCP presents a high-risk diagnostic challenge in the ED. Detecting ACS is particularly important as one-third of ST elevation MI (STEMI) patients die within $24 \mathrm{~h}$ after ischemia onset [5] It has been reported that $46 \%$ of deaths in ED patients are caused by myocardial infarction and $27 \%$ are caused by other ischemic heart diseases $[6,7]$.

In high income countries (HICs) NTCP is the second leading cause of an ED visit after abdominal pain, the symptoms suggestive of myocardial infarction (MI) contributes up to $8-10 \%$ of ED visits yearly and cardiac disease is estimated to be the aetiology in $8-18 \%$ of all cases of chest pain presenting to the $\operatorname{ED}[1,8,9]$. Recent evidence suggests that in the USA, $6 \%$ of NTCP patients in the ED have unrecognized important myocardial damage, and about 3\% of MI patients are erroneously discharged, leading to higher mortality than those admitted [10-12].

There are few studies in Sub Saharan Africa (SSA) describing the aetiology and outcomes of patients with NTCP. The data that does exist suggests that the incidence of NTCP in acute care settings is much lower than in HIC's (1.66\%), respiratory diseases are the most common cause of NTCP, with pneumonia accounting for $24.4 \%$ of patients admitted in this patient population [13, 14], However, as the prevalence of hypertension and diabetes mellitus (DM) increases in these population, the potential for cardiovascular disease has recently gained attention.

Given the paucity of data, and the changing profile of risk factors in SSA, we aimed to determine the incidence, and describe medical evaluation and outcome of adult patients presenting with NTCP to the first full capacity ED in Tanzania. The findings will allow us to understand the aetiologies of NTCP in our population, helping to direct health care resources and establish protocols for evaluation and management.

\section{Methods}

\section{Study design}

This was a prospective observational cohort study of adult patients ( $\geq 18$ years) who presented with NTCP in the emergency medicine department (EMD) of Muhimbili Hospital in Dar es Salaam, from September 2017 to April 2018.

\section{Study setting}

Muhimbili National Hospital (MNH) is a tertiary referral hospital with a bed capacity of 1500 beds, and the main clinical training site for the Muhimbili University of Health and Allied Sciences (MUHAS). The EMD opened in 2010, and it is the site for the only emergency medicine residency training program in the country. The department is staffed by specialist emergency physicians, who provide clinical care, supervision and teaching to interns, registrars (generalists) and emergency medicine residents. The MNH-EMD receives high acuity patients from within Dar-es-Salaam and the surrounding regional and district hospitals; it served over 60,000 patients in 2016.

\section{Study protocol}

A research assistant was present in the department at all times during the study period. All arriving patients were screened for the chief complaint of chest pain by a review of the electronic tracking board. Patients with the chief complaint of non-traumatic chest pain (chest pain unrelated to recent trauma) were approached for consent, and if agreed, enrolled in the study. A standardised case report form was used to document patient demographics, presenting complaints and duration, comorbidities, physical findings, investigations, consultation, and EMD management and disposition. All Electrocardiography were interpreted by ED providers who were attending a patient and consulted cardiology team, chest $\mathrm{X}$ rays were initially interpreted by ED providers and the interpretation were confirmed by the radiology report obtained in the hospital electronic medical record system after being reported by a radiologist. Admitted patients were followed up at $24 \mathrm{~h}$ and 7 days for mortality and final hospital/discharge diagnosis. Data collection was done through interviewing patients and/or next of kin and reviewing the patient's records in the EMD while the patient was still present, and later the hospital patient's medical records for outcomes.

\section{Data analysis}

The data was transferred into a research electronic data capture (REDCap) application and then imported into statistical package for social science (SPSS) (version 23.0.0, IBM LTD, Carolina, USA). Patient characteristics were reported as mean and standard deviation (SD), or median and interquartile range (IQR) for continuous variables and number/proportion for categorical variables. Univariate analysis was used to calculate the relationship between the clinical predictors (abnormal vitals and abnormal investigation results, final hospital diagnosis) and hospital mortality. Relative risk with 95\% Confidence interval $(95 \% \mathrm{CI})$ and Chi-Squire $\left(\mathrm{X}^{2}\right)$ test was used to test the significance of variables association. A $p$ value of $<0.05$ was considered statistically significant.

\section{Results}

We screened 29,495 adults patients 18 years and above who presented to the EMD during the study period; 
among them $430(1.5 \%)$ presented with the complaint of chest pain (traumatic and non-traumatic), and of those, 389 (1.3\%) presented with non-traumatic chest pain. Ten patients refused participation and 30 were missed (discharged prior to enrolment). The remaining 349 consented to participate and were enrolled in the study (Fig. 1).

\section{Patient characteristics}

Of the 349 patients enrolled, median age was 45 years, (IQR: 29-60) years, and 60\% were under 50 years old. There were 177 (50.7\%) females. 194 (55.6\%) patients had at least one comorbidity; hypertension was most common. 43 (12.3\%) arrived to the EMD by ambulance. For 181 (52\%) patients this was the first episode of non-traumatic chest pain. The median duration of current illness was 7 days (IQR 2-30 days). Overall, 99 (28.4\%) patients were referred from other peripheral hospitals. Overall, the most common reported associated symptoms were shortness of breath/difficulty in breathing (SOB/DIB) $31.2 \% n=109$, followed by cough $17.8 \% n=62$, heart beat awareness $(10.6 \% n=$ 37. $38 \% n=132$ patients had increased respiratory rate, $27.4 \% n=95$ had tachycardia, $15.4 \% n=54$ had mean arterial pressure $>110 \mathrm{mmhg}$ and $8.9 \% \quad n=31$ had hypoxia (Table 1).

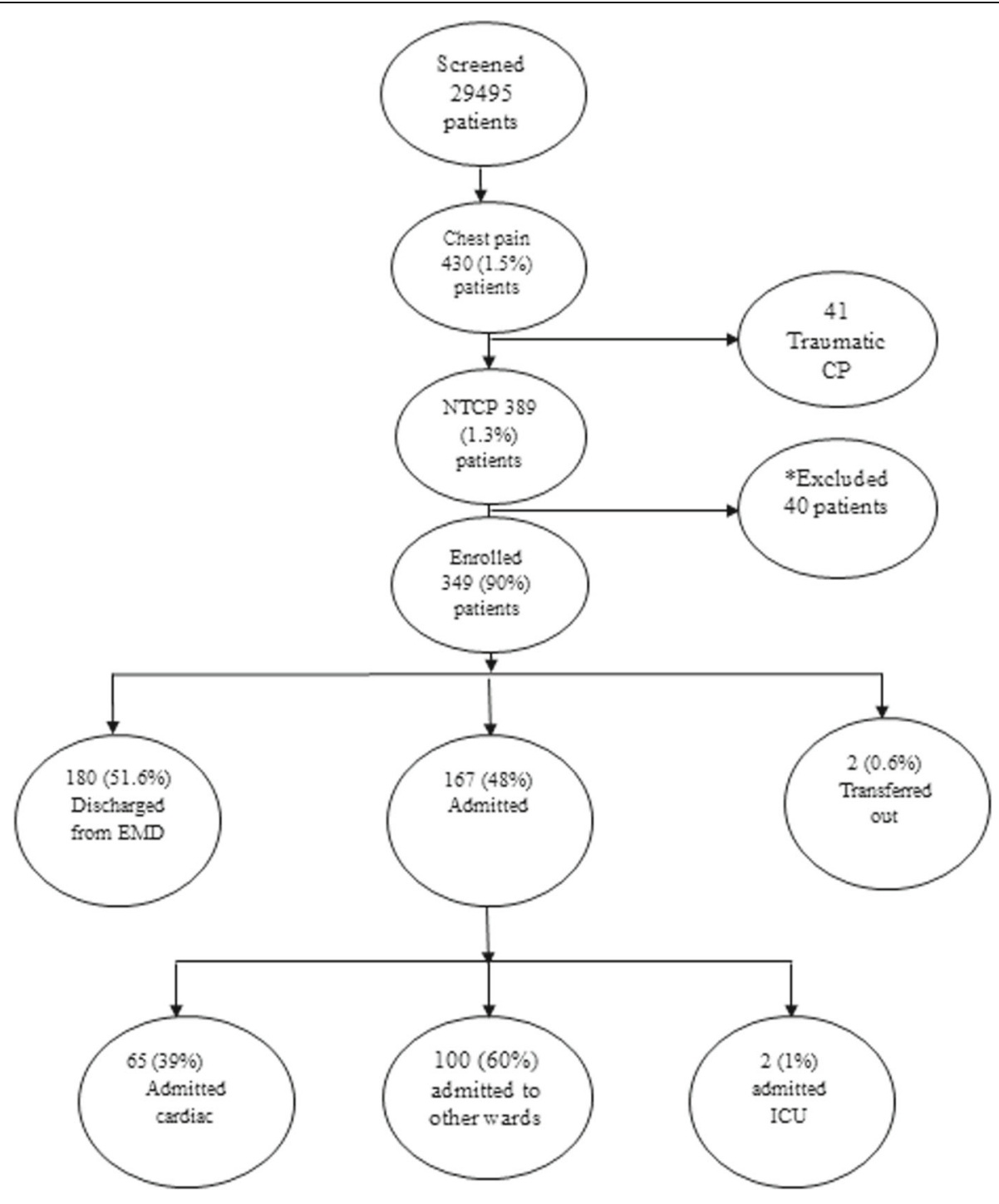

*Excluded 40 patients (10 approached but refused to consent, 30 missed [discharged prior to enrolment]), $C P=$ chest pain, $N T C P=$ non-traumatic chest pain, $I C U=$ intensive care unit

Fig. 1 Screening, enrollment and disposition of adults patients presented to the EMD MNH with the primary complaint of non-traumatic chest pain 
Table 1 Characteristics of study patients

\begin{tabular}{|c|c|}
\hline Variable & Number (\%) \\
\hline Overall & 349 (100\%) \\
\hline Age (years), median (IQR) & $45(29-60)$ \\
\hline Below 50 years & $212(60.7)$ \\
\hline Above 50 years & $137(39.3)$ \\
\hline Female Sex & $177(50.7)$ \\
\hline Common comorbidity & $194(55.6)$ \\
\hline Hypertension & $82(23.5)$ \\
\hline Heart failure & $48(13.8)$ \\
\hline Diabetes Mellitus & $26(7.4)$ \\
\hline HIV infection & $12(3.5)$ \\
\hline Chronic kidney disease & $10(2.9)$ \\
\hline Sickle cell disease & $9(2.6)$ \\
\hline Arrived by ambulance & $43(12.3)$ \\
\hline Arrived by non-ambulance & $306(87.7)$ \\
\hline Referral from peripheral hospitals & $99(28.4)$ \\
\hline Self - referral & $250(71.6)$ \\
\hline \multicolumn{2}{|l|}{ Associated symptoms } \\
\hline Shortness/difficulty in breathing & $109(31.2)$ \\
\hline Cough & $62(17.8)$ \\
\hline Heart beat awareness & $37(10.6)$ \\
\hline Chest tightness & $32(9.2)$ \\
\hline Fever & $29(8.3)$ \\
\hline \multicolumn{2}{|l|}{ Abnormal vital signs } \\
\hline Tachypnea (RR > 20breaths/min at rest) & $132(38.0)$ \\
\hline Tachycardia (HR > 100beats/min at rest) & $95(27.4)$ \\
\hline High MAP (> 110mmhg) & $54(15.4)$ \\
\hline Hypoxia (Spo2 < 94\% in room air) & $31(8.9)$ \\
\hline GCS $<15$ & $20(5.7)$ \\
\hline
\end{tabular}

$H I V$ human Immunodeficiency virus, $R R$ respiratory rate, min minutes, $H R$ heart rate, MAP mean arterial pressure, Spo2 saturation partial pressure of Oxygen, GCS Glasgow comma scale

\section{Patients outcomes}

Among the 349 patients, 167 (48\%; 95\% CI 43-53\%) patients were admitted, 180 (51.6\%) were discharged home from the EMD, $2(0.6 \%)$ were transferred to another hospital. The majority of admissions (57\%) were over 50 years old (Table 2).

Total of $65(39 \%)$ of admitted patients were admitted to the cardiology service (Cardiology Institute,) Two (1.0\%) were admitted to medical ICU and $100(60 \%)$ were admitted to hospital wards according to presumed aetiology and presenting symptoms (Fig. 1).

The $24 \mathrm{~h}$ in-hospital mortality was $3 \%(n=5)$ and the 7 day in-hospital mortality was $9.6 \%(n=16)$, No patient died at EMD (Table 2).
Table 2 Disposition from EMD and outcomes of admitted patients

\begin{tabular}{llll}
\hline & Overall & Patients <50 years & Patients $>50$ years \\
& $\mathrm{N}=349$, & $\mathrm{N}=212$ & $\mathrm{~N}=137$ \\
$\mathrm{n} / \mathrm{N}(\%)$ & $\mathrm{n} / \mathrm{N}(\%)$ & $\mathrm{n} / \mathrm{N}(\%)$ \\
\hline Transferred out & $2 / 349(0.6)$ & - & $2 / 137(1.5)$ \\
Admission & $167 / 349(48)$ & $89 / 212(42)$ & $78 / 137(57)$ \\
$\begin{array}{l}\text { Admitted to } \\
\text { wards }\end{array}$ & $165 / 167(99)$ & $87 / 89(98)$ & $78 / 78(100 \%)$ \\
Admitted to ICU & $2 / 167(1)$ & $2 / 89(2)$ & - \\
Mortality & $\mathrm{N}=167$ & $\mathrm{~N}=89$ & $\mathrm{~N}=78$ \\
24-h mortality & $5 / 167(3)$ & $3 / 89(3.4)$ & $2 / 78(2.6)$ \\
7-day in-hospital & $16 / 167(9.6)$ & $7 / 89(8.0)$ & $9 / 78(11.5)$ \\
mortality & & & \\
\hline
\end{tabular}

\section{ED evaluation}

Among all 349 patients, 69\% had an initial ECG, 47\% of them were abnormal; $34 \%$ had troponin sent, $47 \%$ of them were $>0.04 \mathrm{ng} / \mathrm{ml}$; and $43 \%$ had chest X-ray done, $43 \%$ of them were abnormal (Fig. 2).

\section{Final hospital diagnosis and mortality}

The most frequent final hospital diagnoses were heart failure and pulmonary tuberculosis (PTB) $12.6 \% n=21$ each, followed by chronic kidney disease $10 \% n=17$ and Acute Coronary Syndrome (ACS) $9.6 \%, n=16$. Only the diagnosis of ACS conveyed an increased risk of death. (Table 3) Significant risk factors for mortality were having $\mathrm{ACS}(\mathrm{RR}=5.7), \mathrm{GCS}<15(\mathrm{RR}=3.4)$, Troponin > $0.04 \mathrm{ng} / \mathrm{ml}(\mathrm{RR}-2.9)$ and difficulty in breathing $(\mathrm{RR}=2.8)$ (Table 4). Patients who had cardiovascular disease (CVD) were more likely to have heart rate $<60$ beats per minute (RR 2.6), heart beat awareness (RR 2.3), history of diabetic mellitus (RR 2.2), history of heart disease (RR 2.1 ) and older age $>50$ years (RR 2.1) (Table 5).

\section{Discussion}

In this study, we found that $1.3 \%$ of adult patients presenting to the EMD-MNH had a primary complaint of non-traumatic chest pain (NTCP). Nearly half of patients were admitted, and mortality was $9.6 \%$, higher than in many high income countries (HICs). Most patients presenting with NTCP were young, while the majority of those admitted were $>50$ years. Strengths of this study were that patients were enrolled prospectively and consecutively, with 24-h enrolment during the study period. No admitted patients were lost to follow up and aetiology was based on hospital rather than ED diagnoses. MNH is a referral hospital, and patients are referred to the ED from all over the country.

The frequency of chest pain complaints in our study is lower than that in HICs; studies from EDs in the United states, Europe and United kingdom report that from 2 


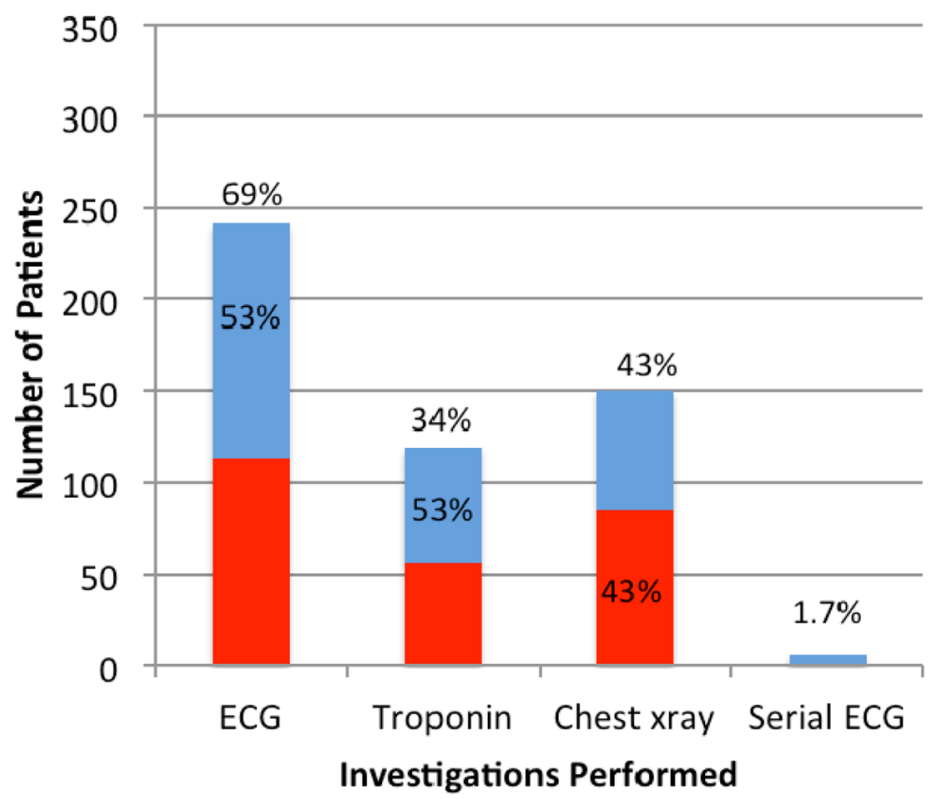

Normal

Abnormal

Fig. 2 EMD most frequent investigations performed and result

to $5 \%$ of patients present with NTCP [5, 15-17]. However, our data are consistent with a study done in Pretoria, South Africa, where $1.66 \%$ of patients presented with NTCP [14].

Our findings are also in contrast to studies done in HICs where the majority of patients presenting to the EMD with NTCP were elderly [18]. In our study, the median age was 45 years. Studies in low and middle income countries (LMICs) have reported a similar age range [13]. This can be partly explained by the differences in etiologies of NTCP, in our study, pulmonary TB was one of the two leading causes of NTCP among those admitted, and patients of any age are at risk, while TB is far less common in HICs. Additionally, hypertension and hypertensive heart disease have an early age of onset in our population, and many patients do not receive timely preventive treatment $[19,20]$.

Previous studies in LMICs reported that respiratory disease is the leading cause of NTCP presentations to emergency departments [14]. However, in this study, heart failure and PTB were equally common as the primary etiologies, followed by CKD and then ACS. The current study also highlights the prevalence of cardiovascular risk factors and the increasing prominence of cardiovascular causes for NTCP in LMICs $[3,21]$ If one includes both heart failure and ACS, cardiovascular disease was among the leading causes of non-traumatic chest pain presentation at EMD (25\%) higher than the

Table 3 Final hospital diagnoses

\begin{tabular}{|c|c|c|c|c|c|}
\hline No & Final Diagnosis & $\begin{array}{l}\text { Overall } \\
\mathrm{N}=167 \\
\mathrm{n}(\%)\end{array}$ & $\begin{array}{l}\text { Alive } \\
N=151 \\
\mathrm{n}(\%)\end{array}$ & $\begin{array}{l}\text { Died } \\
N=16 \\
\mathrm{n}(\%)\end{array}$ & $\begin{array}{l}\text { Relative Risk } \\
(95 \% \mathrm{Cl})\end{array}$ \\
\hline 1. & Heart failure & $21(12.6)$ & $17(11.3)$ & $4(25)$ & $2.3(0.8-6.5)$ \\
\hline 2. & Pulmonary Tuberculosis & $21(12.6)$ & $21(14)$ & - & $0.2(0.01-3.3)$ \\
\hline 3. & Chronic kidney disease & $17(10)$ & $14(9.3)$ & $3(18.8)$ & $2.0(0.6-6.4)$ \\
\hline 4. & Acute coronary syndrome & $16(9.6)$ & $10(6.6)$ & $6(37.5)$ & $5.7(2.4-13.5)$ \\
\hline 5. & Pneumonia & $13(7.8)$ & $13(8.6)$ & - & $0.3(0.02-5.3)$ \\
\hline 6. & Lungs Cancer & $9(5.4)$ & $7(4.6)$ & $2(12.5)$ & $2.5(0.7-9.4)$ \\
\hline 7. & PUD/GERD/Gastritis & $9(5.4)$ & $9(6)$ & & $0.5(0.03-7.5)$ \\
\hline 8. & COPD & $6(3.6)$ & $6(4)$ & - & $0.7(0.05-10.5)$ \\
\hline 9. & Cardiomyopathy & $6(3.6)$ & $6(4)$ & - & $0.7(0.05-10.5)$ \\
\hline 10. & Hypertensive heart disease & $6(3.6)$ & $5(3.3)$ & $1(6.3)$ & $1.8(0.3-11.4)$ \\
\hline 11. & Others & $43(26)$ & $43(28.5)$ & - & \\
\hline
\end{tabular}

COPD chronic obstructive pulmonary disease, PUD peptic ulcer disease, GERD gastro-esophageal reflux disease 
Table 4 Risk factors of in-hospital mortality at 7 days $(N=167)$

\begin{tabular}{lllll}
\hline Variable & $\begin{array}{l}\text { Number } \\
\mathrm{n}\end{array}$ & $\begin{array}{l}\text { Alive } \\
\mathrm{N}=151\end{array}$ & $\begin{array}{l}\text { Dead } \\
\mathrm{N}=16\end{array}$ & $\begin{array}{l}\text { Relative risk } \\
(95 \% \mathrm{Cl})\end{array}$ \\
\hline Age $>$ 50 years & 79 & $71(90)$ & $8(10)$ & $1.1(0.4-2.8)$ \\
History of Diabetic mellitus & 16 & $14(87.5)$ & $2(12.5)$ & $1.35(0.3-5.4)$ \\
Arrived by ambulance & 43 & $39(90.7)$ & $4(9.3))$ & $0.96(0.3-2.8)$ \\
Difficulty in breathing & 73 & $62(85)$ & $11(15)$ & $2.8(1.03-7.8)$ \\
GCS $<15$ & 15 & $11(73.3)$ & $4(26.7)$ & $3.4(1.2-9.1)$ \\
Abnormal ECG & 72 & $62(86)$ & $10(14)$ & $2.2(0.8-5.8)$ \\
Troponin $>0.04$ ng/ml & 35 & $28(80)$ & $7(20)$ & $2.9(1.2-7.3)$ \\
Heart failure & 21 & $17(81)$ & $4(19)$ & $2.3(0.8-6.5)$ \\
Pulmonary Tuberculosis & 21 & $21(100)$ & - & $0.2(0.01-3.3)$ \\
Chronic kidney disease & 17 & $14(82)$ & $3(18)$ & $2.0(0.6-6.4)$ \\
Acute coronary Syndrome & 16 & $10(62.5)$ & $6(37.5)$ & $5.7(2.4-13.5)$ \\
\hline
\end{tabular}

$D I B$ difficulty in breathing, GCS Glasgow coma scale, ECG electrocardiography, $\mathrm{Cl}$ confidence interval

reported $8-18 \%$ in the United Kingdom [1]. Although the proportion of patients presenting with NTCP was lower than in other countries, the admission rate was substantially higher than seen in prior studies [14, 15]. This could be partly due to the lack of alternative sites for evaluation for patients who might have cardiac disease.

One quarter of patients were referred from other hospitals; however, only few arrived by an ambulance. The proportion of patients arriving by ambulance is considerably lower than in the study conducted by Knocker et.al in Belgium [22]. But similar to a study in Pakistan where $<3 \%$ of such patients arrived by ambulance [13]. This difference likely reflects the deficiency of a wellestablished ambulance system and pre-hospital care currently in the most LMICs. The lack of a prehospital care system, as well as generally poor access to care, might also contribute to the delayed presentation as evidenced by the median duration of current illness (7 days) and poor outcomes.

Electrocardiography was performed in more than 50\% of patients, which is similar to findings in other studies in LMICs [13]. This is far lower than would be considered appropriate in HICs and is likely due to generally low suspicion for cardiac disease. Serial ECGs were very rarely performed in our patients. Many patients were discharged home with a single initial ECG and point of care troponin, despite recommendations to perform seserial ECGs to detect acute coronary syndrome, [4, 21]. Troponin was performed in less than half of patients in this cohort, which is higher than frequency of troponin testing in another LMICs study reported $<5 \%$ [13], but lower than in HICs [8]. Thus it is possible, that a number of the patients who were discharged from the ED also had CVD but were not fully evaluated.

In our study, we found a number of factors that predicted cardiovascular aetiologies that can be used by emergency physicians in our setting to guide evaluation. Most of these risk factors have been found in prior studies. However, heart beat awareness is not usually mentioned in evaluation of chest pain but is a common presentation in our setting. Notably, unlike prior studies, we did not find that males had a higher risk of having cardiovascular disease and thus physicians must be equally alert to chest pain in women as in men [7].

Overall, mortality rate of patients presenting with NTCP in our cohort was 9.6\%, higher than reported study in USA $0.8 \%$ [16] and in LMICs < 1\% [13]. Acute coronary syndrome was the most common single cause

Table 5 Risk factor for cardiovascular disease/diagnosis (CVD)

\begin{tabular}{|c|c|c|c|c|}
\hline Risk factor/Presentation & $\begin{array}{l}\text { Number } \\
\mathrm{n}\end{array}$ & $\begin{array}{l}C V D \\
N=65\end{array}$ & $\begin{array}{l}\text { Non CVD } \\
N=102\end{array}$ & $\begin{array}{l}\text { RR for CVD } \\
(95 \% \mathrm{Cl})\end{array}$ \\
\hline Age $>50$ years & 78 & $44(56)$ & $34(44)$ & $2.1(1.4-3.1)$ \\
\hline Male & 81 & $37(45.7)$ & $44(54.3)$ & $1.2(0.9-1.8)$ \\
\hline History of Diabetic Mellitus & 16 & $13(81.3)$ & $3(18.7)$ & $2.2(1.6-3.0)$ \\
\hline History of heart disease & 31 & $22(71)$ & $9(29)$ & $2.1(1.5-2.8)$ \\
\hline History of Hypertension & 47 & $28(59.5)$ & $19(40.5)$ & $2.0(1.4-2.8)$ \\
\hline Difficulty in breathing & 72 & $38(52.8)$ & $34(47.2)$ & $1.5(1.1-2.2)$ \\
\hline Heart beat awareness & 16 & $13(81.3)$ & $3(18.7)$ & $2.3(1.7-3.2)$ \\
\hline Heart Rate $<60$ beats/min & 03 & $3(100 \%)$ & - & $2.6(2.1-3.2)$ \\
\hline MAP $>110 \mathrm{mmhg}$ & 54 & $32(59)$ & $22(41)$ & $2.0(1.4-3.0)$ \\
\hline Initial $S B P \geq 140 / D B P \geq 90 \mathrm{mmhg}$ & 45 & $23(51)$ & $22(49)$ & $1.4(0.9-6-2)$. \\
\hline Heart rate $>100$ beats/min & 63 & $23(36.5)$ & $40(63.5)$ & $0.8(0.6-1.3)$ \\
\hline Hypoxia (SPO2 < 94\% RA) & 26 & $9(34.6)$ & $17(65.4)$ & $0.8(0.5-1.4)$ \\
\hline
\end{tabular}

$M A P$ mean arterial pressure, $S B P$ systolic blood pressure, $D B P$ diastolic blood pressure, $m m h$ millimetre of mercury, $S P O 2$ saturation partial pressure of oxygen, $R A$ room air, $\mathrm{Cl}$ confidence interval 
of death, accounting for nearly $40 \%$ of all deaths, which is comparable with a prior study from LMICs (46\%) [6] but higher than HICs (14.9\%).(1, 23) The higher mortality rate in our population might also be due to a combination of several factors including delayed presentation (median length of NTCP was 7 days), delayed recognition in the EMD, (particularly of ACS, as only few patients received serial ECG and troponin) or limitations in resources, (as only 2 patients were placed in an ICU).

\section{Limitations}

This was a single centre study, which limits generalizability. The information from patient's proxy was used when the patient was too sick to remember, the proxy information might not have been as accurate or as complete as if the patient had given it. Diagnosis was based on the hospital treating physician's diagnosis, rather than adjudicated by a panel of experts. Given the many limitations in our setting for follow-up, we were only able to determine aetiologies for admitted patients and thus the prevalence of serious disease may be higher.

\section{Conclusion}

In this cohort, non-traumatic chest pain was associated with a high admission and mortality rate. ACS was the leading risk factor for death. The main aetiologies of chest pain for admitted patients are PTB and heart failure. Emergency departments and hospitals in these settings should be more alert for the presence of cardiovascular diseases to decrease mortality among patients presenting with NTCP.

\begin{abstract}
Abbreviations
ABG: Arterial blood gases; ACS: Acute coronary syndrome; AMI: Acute myocardial infarction; Cl: Confidence interval; CT Scan: Computed tomography scan; ECG: Electrocardiography; EMD: Emergency medical department; HIV: Human immunodeficiency viruses; ICU: Intensive care unit; IQR: Interquartile range; IRB: Institutional review board; LMIC: Low and middle-income countries; Ml: Myocardial infarction; MNH: Muhimbili national hospital; MUHAS: Muhimbili University of health and allied sciences; PE: Pulmonary embolism; Redcap: Research electronic data capture; SPSS: Statistical package for social science; USA: United state of America
\end{abstract}

\section{Acknowledgements}

The authors would like to acknowledge Dr. Steven Dunlop, Professor Victor Mwafongo, Dr. Juma A. Mfinanga Dr. Phillip Koka, Dr. Upendo George, study participans and members of the the third year residency class for their contributions to this study.

\footnotetext{
Authors' contributions

ASM contributed to conceptualization, data oversee, formal analysis, funding acquisition, methodology, project administration, writing original draft and writing review and editing. HRS was involved in conceptualization, data curation, formal analysis, methodology and supervision as well as revision writing review and editing of the manuscript. BM contributed to conceptualization, data curation, formal analysis, methodology, supervision, writing review and editing of the manuscript. NRM contributed to the conceptualization, revised data analysis, interpretation and the manuscript. KM contributed to the conceptualization, revised data analysis, interpretation and the manuscript. EJW contributed to the conceptualization, revised data analysis, interpretation and the manuscript. All authors read and approved the final manuscript.
}

\section{Funding}

This was a non-funded project; the principal investigators used their own funds to support the data collection and logistics.

\section{Availability of data and materials}

The dataset supporting the conclusion of this article is available from the corresponding author on request.

\section{Ethics approval and consent to participate}

Ethical clearance was obtained from Muhimbili University of Health and Allied Sciences' (MUHAS) Institutional Review Board and permission to collect data was obtained from relevant authorities of both MUHAS and $\mathrm{MNH}$. The study was approved by the Research and Publication authorities at MUHAS. Written informed consent was sought from patients prior to participation in the study.

\section{Consent for publication}

Not applicable.

\section{Competing interests}

The authors declare that they have no competing interest.

\section{Author details}

${ }^{1}$ Emergency Medicine Department, Muhimbili University of Health and Allied Science, P.O. Box 65001, Dar es Salaam, Tanzania. ${ }^{2}$ Emergency Medicine Department, Muhimbili National Hospital, Dar es Salaam, Tanzania. ${ }^{3}$ Department of Emergency Medicine, University of California, San Francisco, CA, USA.

Received: 14 September 2018 Accepted: 12 June 2019

Published online: 28 June 2019

\section{References}

1. Ruigómez A, Rodríguez LAG, Wallander M-A, Johansson S, Jones R. Chest pain in general practice: incidence, comorbidity and mortality. Fam Pract. 2006;23(2):167-74

2. Eslick GD, Fass R. Noncardiac chest pain: evaluation and treatment. Gastroenterol Clin. 2003;32(2):531-52.

3. Emergency Medicine Rosen PDF - emergency-medicine-rosen.pdf. [cited 2017 Feb 28]. http://astrol.avlib.in/emergency-medicine-rosen.pdf

4. The characteristics and management of patients with non-traumatic chest pain in hospital emergency departments. The results of the EVICURE II study (PDF Download Available). Research Gate. [cited 2017 Feb 16];https://www. researchgate.net/publication/242573232

5. Global and chest pain. [cited 2017 Mar 28]. http://www. globalriskinnovations.com/target-solutions/course-platforms/courses-ems/ 68/non-traumatic-chest-pain.html

6. Chest Pain as a presenting complaint in patients with acute myocardial infarction (AMI) (PDF Download Available). Research Gate. [cited 2017 Mar 28]. https://www.researchgate.net/publication/259388073_Chest_Pain_as_a_ presenting_complaint_in_patients_with_acute_myocardial_infarction_AMI

7. troponin-PE-2.pdf. [cited 2017 Feb 18]. http://internalmedicineteaching.org/ pdfs/troponin-PE-2.pdf

8. Kelley WE, Januzzi $J$, Christenson RH. Increases of cardiac troponin in conditions other than acute coronary syndrome and heart failure. Clin Chem. 2009;55(12):2098-112.

9. National Health Statistics Reports, No 7 (August 6, 2008) - nhsr007.pdf. [cited 2017 Feb 17]. https://www.cdc.gov/nchs/data/nhsr/nhsr007.pdf

10. Hess EP, Wells GA, Jaffe A, Stiell IG. A study to derive a clinical decision rule for triage of emergency department patients with chest pain: design and methodology. BMC Emerg Med. 2008;8(1):3.

11. Fernandez Portales J, Perez Reyes F, Garcia Robles JA, Jimenez Candil J, Perez David E, Rey Blas JR, et al. Risk stratification using combined ECG, clinical, and biochemical assessment in patients with chest pain without STsegment elevation. How long should we wait? Rev Esp Cardiol. 2003;56. https://doi.org/10.1016/S0300-8932(03)76876-6.

12. Diagnosis and treatment of chest pain and acute coronary syndrome (ACS). National Guideline Clearinghouse. [cited 2017 Mar 13]. https://www. guideline.gov/summaries/summary/39320

13. Paichadze N, Afzal B, Zia N, Mujeeb R, Khan MM, Razzak JA Characteristics of chest pain and its acute management in a low-middle income country: 
analysis of emergency department surveillance data from Pakistan. BMC Emerg Med. 2015;15(Suppl 2):S13.

14. Geyser M, Smith S. Chest pain prevalence, causes, and disposition in the emergency department of a regional hospital in Pretoria. Afr J Prim Health Care Fam Med. 2016 [cited 2017 Feb 17]; 8(1). http://www.ncbi.nlm.nih.gov/ pmc/articles/PMC4926718/

15. Miller CD, Lindsell CJ, Anantharaman V, Greenway J, Pollack CV, Tiffany BR, et al. Performance of a population-based cardiac risk stratification tool in Asian patients with chest pain. Acad Emerg Med. 2005;12. https://doi.org/10 1197/j.aem.2004.11.016.

16. Walker NJ, Sites FD, Shofer FS, Hollander JE. Characteristics and outcomes of young adults who present to the emergency department with chest pain. Acad Emerg Med. 2001;8. https://doi.org/10.1111/j.1553-2712.2001.tb00188.x

17. Singh SS, Paul SK, Pal R, Thatkar PV. Acute coronary syndrome-related mortality audit in a teaching hospital at Port Blair. India J Fam Med Prim Care. 2017;6(3):502-8.

18. Kontos MC, Diercks DB, Kirk JD. Emergency department and office-based evaluation of patients with chest pain. Mayo Clin Proc. 2010;85(3):284-99.

19. Cappuccio FP, Miller MA. Cardiovascular disease and hypertension in sub-Saharan Africa: burden, risk and interventions. Intern Emerg Med. 2016;11:299-305.

20. Bragulat E, López B, Miró Ó, Coll-Vinent B, Jiménez S, Aparicio MJ, et al. Performance assessment of an emergency department chest pain unit. Rev Esp Cardiol Engl Ed. 2007;60(03):276-84

21. Herren KR, Mackway-Jones K, Richards CR, Seneviratne CJ, France MW, Cotter $L$. Is it possible to exclude a diagnosis of myocardial damage within six hours of admission to an emergency department? Diagnostic cohort study. BMJ. 2001;323(7309):372.

22. Chest pain in the emergency department: the broad spectrum o... : European Journal of Emergency Medicine. LWW. [cited 2017 Mar 30]. http:// journals.Iww.com/euro-emergencymed/Fulltext/2002/03000/Chest_pain_in_ the_emergency_department_the_broad.7.aspx

\section{Publisher's Note}

Springer Nature remains neutral with regard to jurisdictional claims in published maps and institutional affiliations.

Ready to submit your research? Choose BMC and benefit from:

- fast, convenient online submission

- thorough peer review by experienced researchers in your field

- rapid publication on acceptance

- support for research data, including large and complex data types

- gold Open Access which fosters wider collaboration and increased citations

- maximum visibility for your research: over $100 \mathrm{M}$ website views per year

At $\mathrm{BMC}$, research is always in progress.

Learn more biomedcentral.com/submissions 